\title{
CULTURA LÚDICA E MEDIAÇÕES NO CONTEXTO ESCOLAR
}

Paloma Ariel R. Freitas, José Milton de Lima.

Universidade Estadual Paulista - UNESP, Departamento de Educação, Presidente Prudente, SP. E-mail: paloma.arf27@gmail.com.

\section{RESUMO}

Pensando no desenvolvimento do sujeito mediante suas vivencias e experiências dentro e fora do contexto escolar, assumimos como pesquisa compreender as manifestações televisivas nas culturas lúdicas das crianças dentro de uma instituição de ensino do Oeste Paulista. A metodologia utilizada foi de natureza qualitativa, caracterizando-se como Pesquisa do tipo Etnográfica, usamos de entrevistas, observações e anotações em diário de campo, nossas observações apontam que a mídia televisiva se encontra presente na instituição escolar, sendo percebida em diversos momentos como nas conversas das crianças e nas atividades lúdicas infantis. Também pudemos perceber a manifestação televisiva através do consumismo, que aparece significativamente nas estampas de roupas, calçados e objetos que as crianças trazem para dentro da instituição, e ainda, percebeu-se que a mediação dentro da escola não é realizada como deveria, a fim de ressignificar e proporcionar senso crítico com potencial de modificar a relação da mídia com as crianças.

Palavras-chave: Infância, Ludicidade, Mídia, Mediação, Escola.

\section{LEISURE CULTURE AND MEDIATIONS IN THE SCHOOL CONTEXT}

\begin{abstract}
Thinking on the development of the subject through their livings and experiences within and outside the school context, we assume, as research understand television demonstrations in playful cultures of children within an educational institution in the West. The methodology used was qualitative in nature, characterized as Ethnographic type lookup, use of interviews, observations and notes in field journal, our observations indicate that the television media is present in the school institution, being perceived in various moments and in conversations of children and children's leisure activities. We could also see the demonstration televisiva through consumerism, which appears significantly in prints of clothes, footwear and objects that children bring into the institution, and yet, it was noticed that the mediation within the school is not held as it should, in order to redefine its meaning and provide critical sense with the potential to change the relationship of the media with the children.
\end{abstract}

Keywords: Childhood, Playfulness, Media, Mediation, School. 


\section{INTRODUÇÃO}

Com o avanço da modernidade houve mudanças na forma de viver e conviver, cada sociedade traz consigo formas de socialização, um dos lugares que começam a ser estimuladas as vivencias em conjuntos é a escola, que tem um papel fundamental no desenvolvimento. Sabemos que o processo de educação tem todo um contexto, portanto as crianças já chegam na escola com saberes vindo dos pais, amigos, vizinhos e meios informativos como as mídias.

O ensino começa na educação infantil que por sua vez tinha caráter de assistência social, ou seja, caráter de cuidados para com as crianças, não tinha nenhum indicio de práticas escolares. Mas, depois da constituição de 1988 determinou-se do ponto de vista legal que "a Educação Infantil é a primeira etapa da Educação Básica e tem como finalidade o desenvolvimento integral da criança de zero a cinco anos de idade em seus aspectos físico, afetivo, intelectual, linguístico e social, complementando a ação da família e da comunidade" (BRASIL, 2009, p. 03).

Sendo assim a escola que irá atender crianças de etnias, culturas e classes econômicas diferentes, terá que lidar dar com informações divergente. As crianças vêm para escola com informações sobre o mundo formadas a partir de vivencias e conivências, informações essas que por muitas vezes é adquirida através de mídias como a internet e televisão.

Em especial as crianças passam muito tempo em frente a uma televisão, e com isso adquirem conhecimento e ideias que posteriormente será usada na formação de novas brincadeiras com seus amigos e família, a televisão é uma forte fomentadora das culturas lúdicas.

Portanto nosso objetivo foi compreender as manifestações televisivas nas culturas lúdicas das crianças dentro da instituição de ensino, tomando que a cultura lúdica é produzida por vivencias e suas trocas, dentro e fora do contexto escolar.

\section{METODOLOGIA}

Para se realizar uma pesquisa é preciso promover um confronto de dados, evidências, informações coletadas, e conhecimento teórico acumulado a respeito (LUDKE; ANDRÉ, 1986). Seguindo estes requisitos, pretendemos investigar os elementos culturais de uma instituição de Educação Infantil no interior do Oeste Paulista, visando compreender e interpretar os fenômenos sociais com base nas perspectivas dos atores, por intermédio do envolvimento e presença semanal da pesquisadora no ambiente escolar.

Para tanto, em busca de elucidar esses objetivos, utilizaremos da metodologia qualitativa, que não tem uma dimensão quantificável, mas sim interpretativa. Segundo Richardson $(1989$, p.6) uma metodologia qualitativa:

[...] pode descrever a complexidade de determinado problema, analisar a interação de certas variáveis, compreender e classificar processos dinâmicos vividos por grupos sociais, contribuir no processo de mudança de determinado grupo e possibilitar, em maior nível de profundidade, o entendimento das particularidades do comportamento dos indivíduos.

Utilizamos da pesquisa do tipo etnográfica, segundo Ludke e André (1986, p.14) "a etnografia é a descrição de um sistema de significados culturais de um determinado grupo".

A pesquisa se caracteriza como do tipo etnográfica, por que na área educacional, há alguns requisitos adaptáveis, ou seja, que não necessitam ser rigidamente seguidos, como, por exemplo, uma longa permanência do pesquisador no campo de pesquisa, o contato com outras culturas e o uso de muitas categorias sociais de análise, assim o que se faz é uma adaptação do estudo etnográfico (ANDRÉ, 2003).

É importante destacar que a pesquisa, pode ser assim nomeada - do tipo etnográfica - pois faz uso das principais técnicas tradicionalmente associadas à etnografia, ou seja, a observação participante, a entrevista intensiva e a análise de documentos. 
Sobre o papel do etnógrafo, mantemos uma postura cooperativa, de diálogo, de modo que os sujeitos da pesquisa possam vir mostrar o que pode ser feito para mudar o campo de pesquisa, sendo assim, as relações entre pesquisador e pesquisado são fundamentais. Dito isto, ressaltamos que esta pesquisa é feita com crianças e não sobre crianças. Concebendo-as como atores sociais, sujeitos de direitos, sustentando a indispensabilidade da participação infantil como uma questão social, política e cientifica, além de valiosos no diálogo de negociação de sentidos e significados.

O grupo pesquisado é formado por aproximadamente 180 crianças de 4 a 5 anos e 8 educadoras de uma instituição de Educação Infantil, localizada no interior do Oeste Paulista. As observações ocorrem uma vez na semana, no período da manhã e da tarde, quando a pesquisadora permanece na escola.

Por meio da observação participante, podemos entender a cultura da criança, participando das suas brincadeiras e do seu cotidiano, nos tornamos o que Corsaro (2005) entende, e praticou em suas pesquisas, um adulto atípico, aquele que como um amigo especial, tem melhores condições de buscar interpretar o mundo como a criança a enxerga, criando um ambiente de convivência, confidências, podendo apreender a visão e o significado que eles atribuem as suas realidades.

Em relação aos procedimentos metodológicos, a pesquisa utilizou técnicas de observação, entrevistas, questionários, levantamentos bibliográficos e diário de campo. Tal escolha se justifica, pois, estas técnicas auxiliam no levantamento de dados que permitem desvelar complexidade do problema (RICHARDSON, 1989).

As observações aconteceram uma vez por semana, durante todo o período letivo. A pesquisadora acompanhou, em média de cinquenta minutos, as atividades lúdicas das turmas e anotava em diário de campo as relações entre crianças / adultos e crianças / crianças, ressaltando também suas atitudes, diálogos e expressões.

Ademais, a base teórica, conta com as contribuições, através da discussão de materiais sobre a Sociologia da infância, que ocorrem quinzenalmente, no CEPELIJ, Centro de Estudos e Pesquisa em Educação, Ludicidade, Infância e Juventude, que conta também com os aportes de mestrandos, doutorando e docentes da UNESP, e foi autorizado pelo comitê de ética em pesquisa de número 13424213800005402.

\section{RESULTADOS}

A partir da metodologia proposta, a pesquisa do tipo etnográfica, constatamos que nossa principal ferramenta era a observação e assim conseguimos com a ajuda da fundamentação teórica construída, entender muitas das situações que se apresentavam no contexto escolar. Desta maneira, pudemos através de conversas e atitudes das crianças perceber a importância que a televisão tem em suas vidas, visto que ela repercute dentro do ambiente escolar.

Percebemos com o estudo, que a mídia televisiva se encontra visualmente dentro do ambiente escolar com o consumismo, ou seja, através dos desenhos infantis estampando camisetas, shorts, chinelos, mochilas, tênis, entre outros acessórios, que ajudam as crianças quando falam de um determinado personagem e usam a imagem para nos explicar.

Temos que considerar que produtos com estampas de desenhos animados são por lógica de mercado mais caros, mas isso não impede que essa cultura entre pelas portas de nossa escola. Nesse sentido, apresentamos algumas das fotografias realizadas durante a pesquisa mostrando esse consumo. $O$ destaque ficou para a animação Frozen da Disney que mais apareceu no período da pesquisa.

As preferências que as crianças demonstraram durante nossas observações, caracterizaram-se como próprias para sua idade, todas as crianças quando conversavam sobre os conteúdos televisivos apresentavam os desenhos infantis, sem mencionar novelas e outros gêneros que possamos pensar que fazem parte também das culturas dos pequenos. 
Além disso, percebemos que as crianças utilizam esses determinados conteúdos como linguagem corporal, reconhecendo por música e gestos as suas preferências na tela. Uma das crianças, Maria ${ }^{1}$ segundo Diário de campo (04 de dezembro de 2015), nos ensinou a brincar de "Pega-Pega Frozen", através de suas regras pudemos perceber que é o antigo Pega-congela, só que Maria nos proporcionou imaginar que o Pegador seria a Elsa (Personagem da animação) e congelaria a todos. Brincamos perto da hora do recreio e as crianças aparentava gostarem muito.

Outro destaque da ludicidade e televisão são os DVDs da Xuxa que invadem os muros da escola. Foi reconhecida a música que tocava na creche ao lado da escola e uma criança nos avisou no intervalo, e ainda quando as bolsistas do projeto de extensão passaram.

Imperativo se faz destacar que as brincadeiras se fazem extremamente importantes para as crianças, e devem ser muito valorizadas na infância e cada momento deve ser aproveitado. Percebemos em uma observação a preocupação das crianças quanto à ludicidade. Em dezembro, quando falei com elas sobre as férias escolares, elas me perguntaram se iria ter brincadeiras, como as meninas do projeto de extensão faziam com elas.

Sobre a conduta das professoras, aplicamos um questionário para as 8 educadoras da instituição sobre o brincar e a hora do vídeo, que é o momento de pode ocorrer uma mediação situacional de algum conteúdo. Citaremos algumas perguntas e suas respostas em geral.

Uma das questões foi sobre a concepção das professoras sobre a hora do vídeo. A maioria entende que o filme a ser passado tem que estar de acordo com o conteúdo a ser trabalhado, e assim utilizam como outra forma de fixar determinado conteúdo. A pergunta seguinte era sobre como eram escolhidos os filmes, sendo assim, de acordo com a primeira resposta eram filmes que tivessem diálogo com o conteúdo trabalhado.

Outra pergunta foi se as professoras costumavam aplicar atividades sobre o filme da hora do vídeo. A maioria das educadoras respondeu que costuma pedir que façam registros e ilustrações sobre o que entenderam, ou mesmo a mensagem que o filme passou, para ver se eles realmente prestaram atenção e se apropriaram.

Uma das perguntas mais importante foi "As crianças trazem brinquedos para à escola? Qual a sua concepção sobre o brinquedo? ", necessário se fez descrevê-la devido a sua importância no relatório e ainda as diversas opiniões. Algumas respostas foram

"De grande importância, por meio do brincar, as crianças produzem o que sente i que pensa, através do faz de contra, do lúdico" (Professora do Infantil I);

"Esse trabalho ('Dia do brinquedo') se encontra em nosso planejamento, porém não teve início ainda, provavelmente no segundo semestre quando esperamos uma maior autonomia e zelo por parte dos alunos em relação aos seus pertences e aos dos amigos. Considero o brinquedo algo muito importante para o desenvolvimento da criança em seus mais diferentes aspectos" (Professora do Infantil I);

"Na sexta-feira, dia do brinquedo. Um momento em que a criança interage com o outro em vários aspectos". (Professora do Infantil II);

"Sim, trazem na sexta-feira que é o dia do brinquedo. Através do brincar desenvolvem a imaginação e a socialização entre eles. " (Professora do Infantil II).

Desta maneira, entendemos que todas as professoras sabem a importância que o brinquedo e a brincadeira têm para as crianças, mas a forma que elas expressam esta brincadeira ainda não é plenamente valorizada devido ao tempo que observamos que elas têm para essa atividade.

Ao aprofundar os estudos sobre as múltiplas significações das palavras lúdico, ludicidade, atividade lúdica, brincadeira, entre outras, pudemos perceber que não podemos tratar todas como sinônimos, visto que são diferentes conceitos que devem ser respeitados na hora da teoria e da prática ao observar os pequenos.

\footnotetext{
${ }^{1}$ Nome fictício
} 
Algumas das falas e a apropriação nos movimentos sejam eles tirados de DVDs ou mesmo de brincadeiras criadas pelas crianças, demonstram em consonância do que afirma Saura (2014) que a mídia pode ser observada na cultura corporal de movimento em vários momentos lúdicos.

\section{DISCUSSÃO}

A nossa discussão começa com Sarmento e seu artigo publicado em 2002, ele apresenta argumentos sobre a 2ㅇ modernidade, um deles é sobre a extensão de novas modalidades de vida, com o progressivo envolvimento dos adultos na cultura do lazer, e com consequências e efeitos pouco previsíveis.

Sendo assim, consideramos de fato importante investigar as mídias como novas modalidades de vida e de linguagem dos pequenos, buscando conhecer efeitos dessa tecnologia em suas culturas, dando ênfase na cultura televisiva e sua relação com a ludicidade.

A Televisão revelou-se como o meio de comunicação mais presente na expressão das crianças, segundo nossa pesquisa e a de Costa e Betti (2006), sendo um integrante enraizado do ambiente escolar e que se reflete também na cultura lúdica.

A mídia televisiva revelou-se como o aparelho que $98 \%$ das crianças tem em sua casa, de acordo com um questionário que aplicamos com os pais dos nossos sujeitos. Os desenhos animados apareceram como o programa de televisão mais assistidos por $80 \%$ delas. Assim como na pesquisa de Siqueira, Wiggers e Souza (2012) compreendemos que os conteúdos midiáticos se caracterizaram como uma referência comum na criação das experiências lúdicas dessas crianças.

Brougère (2000) argumenta que precisamos entender que a mídia dentro da cultura lúdica é o resultado da impregnação cultural, da saída da posição de observador de uma imagem para o ator da atividade lúdica, não apenas a incorporação de simbolismos sem sentido.

Como destaca Betti (2003) a televisão tem um conteúdo muitas vezes pobre, porém é "semioticamente complexa". Ele a considera estimuladora do aprendizado cognitivo e psicológico. Em concordância com Girardello (2005) entendemos que cada indivíduo interpreta e relaciona as mensagens vinculadas de acordo com as suas vivências socioculturais e psíquicas.

Munarim (2007) é categórica quando afirma que a infância é construída com a ajuda da mídia, porque ela está tão imbricada que faz parte da cultura contemporânea. Brougère (2000) disserta que para ele, a televisão modifica e interfere significativamente na cultura lúdica a partir do que as crianças têm contato.

Quando adentramos na escola, a primeira coisa que nos chama atenção para a mídia são as camisetas, bonés, estojos, mochilas estampadas com conteúdo televisivos, e eventualmente brinquedos.

Segundo Siqueira, Wiggers e Souza (2012) com a importância da mídia e suas influências atualmente dentro da escola, torna-se necessário tirar o autodidatismo, como destacam Orofino e Girardello (2011) para que haja uma preparação e esclarecimentos da comunidade de educadores para orientar suas práticas pedagógicas.

De acordo com Orozco Gomes (1997 apud SIQUEIRA, WIGGERS E SOUZA, 2012) a escola se torna importante nessa questão, pois se oferece como um espaço onde as crianças manifestam os conteúdos absorvidos e que podem ser ressignificados, também como um espaço formativo e informativo para a interação crítica e esclarecedora sobre as mensagens. Vê-se necessária, segundo o autor, uma intervenção pedagógica, visto que haverá um conflito no que é ensinado e aprendido a escola e na TV.

É preciso que a escola aceite as realidades do seu tempo para se preparar adequadamente para enfrentar as dificuldades considerando que é na escola que o pensamento é fértil e sobrevivente (SIQUEIRA, WIGGERS E SOUZA, 2012, p.317). 
Assim, não surpreende que o comportamento das crianças e suas brincadeiras repercutam os conteúdos televisivos, mas cresce ainda mais a percepção de que a escola necessita atuar na perspectiva de integrar mídia e educação. Fazem-se necessários estudos que ampliem a compreensão das crianças e suas relações com as mídias, dando voz a elas para que depois se apliquem propostas capazes de desenvolverem um olhar crítico das crianças sobre as mídias.

\section{CONCLUSÃO}

Através da escuta atenta, do olhar que enxerga além do adulto que se tornará, com o auxílio do arcabouço teórico construído, pudemos constatar que os conteúdos televisivos estão dentro do ambiente escolar. Estão nas vestimentas, nas falas, e principalmente na cultura corporal e nas brincadeiras.

A Cultura televisiva é importante na vida das crianças, e assim como as atividades lúdicas devem ser valorizadas na educação infantil e percebemos que não são como deveriam, os conteúdos televisivos podem ajudar na apropriação dos saberes da sala de aula, na valorização das suas falas, na sua maneira de socializar, e podem ser reconhecidas nesse contexto.

Os conceitos mostrados sobre brincar, jogo, brinquedo, atividade lúdica, ludicidade e as tendências pedagógicas hoje, nos mostram o quanto ainda precisamos caminhar para entender a temática e construir uma prática sólida.

Pois conhecer a mídia nesse contexto de industrialização e modernidade com que as crianças já chegam na escola só tem a acrescentar. A temática é um estimulo para conhecer as crianças da modernidade, saber como lhe dar com elas, como chamar sua atenção.

Refletir sobre a questão do lugar e tempo na educação das crianças é buscar uma educação equilibrada. Cada criança tem seu tempo e lugar para viver sua infância adequadamente. Só não devemos submeter a lógica da criança pelo pensamento adultocêntrico para que sejamos de fato facilitadores de uma infância rica em experiências e não sejamos aqueles que os veem como adultos em miniatura como outrora foram (mal) compreendidos.

A infância segue cada vez mais um padrão dentro da educação, cada vez mais as crianças estão perdendo seu espaço de brincar, podemos mudar isso com práticas pedagógicas que ao mesmo tempo que as crianças brincam elas possam estar aprendendo.

Para contribuir com uma escola que receba suas crianças com maior entendimento de quem são, que não tire seu tempo de brincar, que possa usar as mídias como forma de ensinar, uma forma menos cansativa e mais atrativa.

Dessa maneira, creio que estamos no caminho certo para conseguir bons resultados que nos ajudem a entendermos essa infância que tanto queremos e o efeito dessa mídia que nos instiga e que encantam os pequenos.

\section{REFERÊNCIAS}

ANDRÉ, M. E. D. A. Etnografia da prática escolar. Campinas: Papirus, 2003

BOCHORNY, J. Cultura lúdica e televisão: mediações no contexto escolar. 2012. 157 f. Dissertação (Mestre) - Universidade Estadual Paulista "Júlio de Mesquita Filho", Presidente Prudente, 2012.

BETTI, M. Imagem e ação: a televisão e a Educação Física escolar. In: BETTI, Mauro (org.). Educação Física e Mídia: novos olhares outras práticas. São Paulo: Hucitec, 2003.

BRASIL. Diretrizes Curriculares Nacionais para a Educação Infantil. Brasília, 2009.

BROUGÈRE, G. Brinquedo e cultura. 3. ed. São Paulo: Cortez, 2000. 110p. Coleção Questões da Nossa Época, v.43. 
CORSARO, W. A. Sociologia da Infância. Porto Alegre: Artmed; 2011.

. Entrada no campo, aceitação e natureza da participação nos estudos

etnográficos com crianças pequenas. Educação e Sociedade, Campinas, v.26, n.91, p.443-464, Maio/ago. 2005

DELGADO, A. C. C.; MULLER, F. Em busca de metodologias investigativas com as crianças e suas culturas. Cad. Pesqui. [Online]. 2005, vol.35, n.125, pp. 161-179. ISSN 0100-1574.

GIRARDELLO, G. Imaginação infantil e as histórias da TV, 2005. Disponível em: <www.aurora.ufsc. br/artigos/artigos_imaginacao.htm>. Acesso em: jun. 2008.

GIRARDELLO, G; OROFINO, I. Uma mirada sobre educación y médios en Brasil. Infoamérica, 2011, p 113- 122.

LUDKE, M.; ANDRÉ, M. E. D. A. Pesquisa em Educação: abordagens qualitativas. São Paulo: EPU, 1986.

MUNARIM, I. Brincando na escola: o imaginário midiático na cultura de movimento das crianças. 2007. 194f. Dissertação (Mestrado em Educação) - Universidade Federal de Santa Catarina.

Florianópolis.

RICHARDSON, R. J. Pesquisa Social: métodos e técnicas. São Paulo: Atlas, 1989.

SARMENTO, M. J. As culturas da Infância nas encruzilhadas da 20 modernidade. 200/3. Disponível em <http://cedic.iec.uminho.pt/cedic/Textos_de_Trabalho/textos/encruzilhadas.pdf $>$. Acesso em 05/05/2007.

SIQUEIRA, I. B.; WIGGERS, I. D.; SOUZA, V. P. O brincar na escola: a relação entre o lúdico e a mídia no universo infantil. Rev. Bras. Ciênc. Esporte [online]. 2012, vol.34, n.2, pp. 313-326. ISSN 01013289. 